\title{
Maxillofacial radiology case 161
}

\author{
SADJ June 2018, Vol 73 no 5 p367
}

\section{CJ Nortje}

Below are images of a condition caused by a deficiency of organic bone matrix; however, there is normal mineralization of the remaining bone. This condition is a common disorder affecting post-menopausal middle-aged women.What are the important radiological findings and diagnosis?

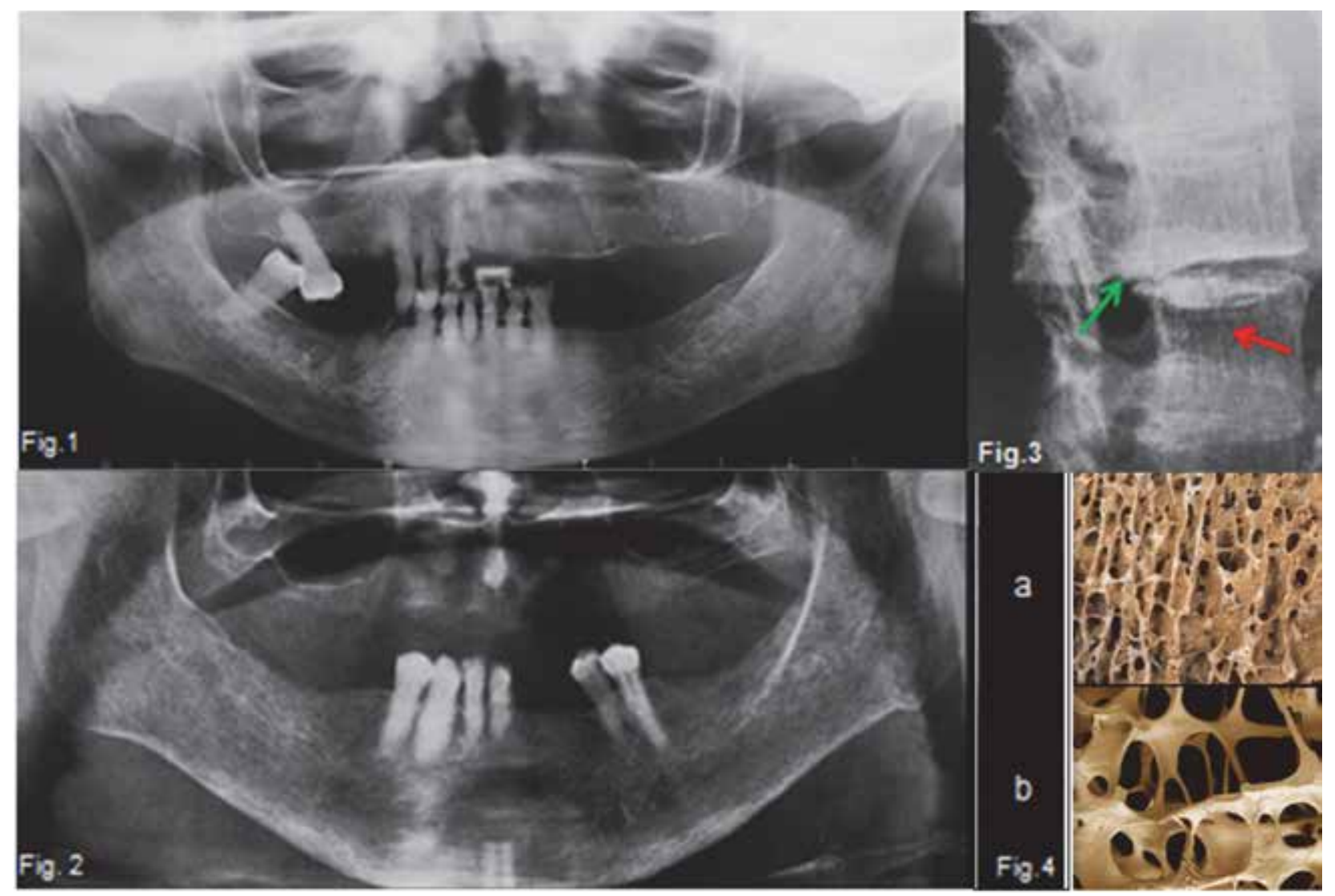

\section{INTERPRETATION}

A figure 1 and 2 are pantomograhs of two elderly woman shows thinning of the cortex at the inferior border at the angle of the mandible. There are cortical laminations with endosteal detachment. The alveolar bone is denser (darker) than normal, although the teeth are exposed correctly; trabeculae are fewer in number, coarser and showing reduced density. Figure 3 of another patient shows a classic appearance of the same condition in the vertebral column; loss of horizontal trabeculae; thicker, more prominent vertical trabeculae; and more radiolucent vertebral body (red arrow). The posterior vertebral plate is coarser, with irregular endosteal surface. There is a wedge-shaped deformity of the disk, as can be seen by the V-shape of the intervertebral space (green arrow). In several places there is complete loss of the intervertebral space. A diagnosis of osteoporosis was made in all these cases. Figure 4 demonstrates changes from normal bone (a) to severe osteoporosis (b). Primary osteoporosis refers to a condition that is not associated with any of the diseases known to cause an osteoporotic state. No known causal condition has been established. According to Garn (1970), normal bone mass increases as a person progresses from infancy to 30 to 40 years of age and then decreases continuously at a rate of $8 \%$ per decade

CJ Nortjé: $B C h D, P h D, A B O M R$, DSc. Faculty of Dentistry, University of the Western Cape. E-mail: cnortje@uwc.ac.za in women and $3 \%$ in men. This bone loss is particularly evident in the cortex and continuous until a person dies. Fifty percent of men exhibit cortical bone erosion by age 80; among women, $50 \%$ show cortical bone loss by the age of 70 and $100 \%$ by age 90 . Trabecular bone is affected earlier than cortical bone, and the vertebral column is the prime site of advanced cases. In women osteoporosis results from increased resorption that is associated with menopause. During menopause, there is diminished production of oestrogens, which tend to protect the skeleton against the resorbing action of parathyroid hormone. In men primary osteoporosis may develop from diminished androgen production. It has been shown in aging men that parathyroid levels increase, yet urinary excretion of calcium decreased with age. It is presumed that there is an increased tubular resorption of ionic calcium resulting from mild secondary hyperparathyroidism. This calcium-saving mechanism is missing in women. Regardless of the cause, osteoporosis results in an increase of fractures in the axial skeleton and possibly tooth loss and alveolar ridge resorption in the jaws.

\section{References}

1. Farman AG, Nortjé CJ \& Wood R E: Oral and Maxillofacial Imaging, 1st Ed, Mosby. St. Louis, Missouri 1993 pp. 342-344.

2. Langlais RP, Langland OE \& Nortje CJ: Diagnostic Imaging of the Jaws 1st Edition, Williams \& Wilkins, 1995, pp. 451-454.

3. Garn SM: The Earlier Gain and the Later Loss of Cortical Bone in Nutritional Perspective. Springfield, IL: Charles C Thomas, 1970. P. 231. 